\title{
DELIMITAÇÃO DE MICROBACIAS HIDROGRÁFICAS A PARTIR DE UM PONTO DE EXUTÓRIO ESPECÍFICO (POUR POINT) UTILIZANDO DADOS SRTM
}

\author{
Hullysses Sabino $^{(\mathrm{a})}$, Gustavo M. Vasques ${ }^{(\mathrm{b})}$, Ricardo O. Dart ${ }^{(\mathrm{b})}$, Luís Carlos Hernani ${ }^{(\mathrm{b})}$ \\ (a) Departamento de Geografia, Universidade Federal Fluminense, Niterói/RJ, hsabino@id.uff.br \\ (b) Embrapa Solos, RJ/Rio de Janeiro, gustavo.vasques@embrapa.br, ricardo.dart@embrapa.br, \\ luis.hernani@embrapa.br
}

\section{EIXO: BACIAS HIDROGRÁFICAS E RECURSOS HÍDRICOS: ANÁLISE, PLANEJAMENTO E GESTÃO}

\begin{abstract}
Resumo
Apesar da crescente demanda por delimitação digital de bacias hidrográficas, os métodos disponíveis para tal normalmente não utilizam pontos específicos de exutório e, com isso, não controlam a ordem ou o tamanho da bacia delineada. O objetivo foi aplicar um método para delimitar microbacias hidrográficas usando pontos de exutório, controlando mais precisamente o tamanho das mesmas. Modelos Digitais de Elevação (MDE's) da Shuttle Radar Topography Mission (SRTM) com pixel de $30 \mathrm{~m}$ e pontos de exutório foram usados para delimitar doze microbacias hidrográficas usando ferramentas de análise hidrológica do ArcGIS. Para conferir as bacias delineadas, MDE's e imagens multiespectrais com pixel de $1 \mathrm{~m}$ foram usadas. O método aplicado usando MDE's da SRTM de $30 \mathrm{~m}$ delineou as microbacias hidrográficas em conformidade com as bases cartográficas de alta resolução espacial. Além de usar dados da SRTM gratuitos, o método possui aplicação simples no ArcGIS e possibilita produzir resultados padronizados.
\end{abstract}

Palavras-chave: Modelo digital de elevação, Geoprocessamento, ArcGIS

\section{Introdução}

O conhecimento da área englobada por uma bacia hidrográfica é essencial para os estudos de suas características físicas, de uso e cobertura da terra e para sua adequada gestão e planejamento. No Brasil, órgãos públicos como a Agência Nacional de Águas e o Instituto Brasileiro de Geografia e Estatística oferecem dados referentes às bacias hidrográficas, contudo, não se encontram disponíveis muitas informações de pequenas bacias. Por conta disto, em muitos casos faz-se necessária a delimitação das bacias hidrográficas nas escalas específicas de interesse.

Um dos métodos mais conhecidos para demarcar bacias em ambiente de Sistema de Informações Geográficas (SIG) utiliza Modelos Digitais de Elevação (MDE's), os quais armazenam dados de altimetria da superfície terrestre e possibilitam derivar informações sobre a geomorfologia, declividade, hidrologia, ou seja, permitem uma ampla análise morfológica e hidrológica das feições terrestres. Esses métodos 
remontam da década de 1980, a partir de trabalhos de delineamento de redes de drenagem usando MDE's (MARK, 1984; JENSON; DOMINIQUE, 1988).

Após os primeiros trabalhos no tema, um grande salto no volume de dados de MDE disponíveis ocorreu em 2000, quando a National Aeronautics and Space Administration (NASA) e a National GeospatialItelligence Agency (NGA) realizaram a Shuttle Radar Topography Mission (SRTM), que gerou MDE's com pixel de 30 m recobrindo mais de $80 \%$ da superfície terrestre.

Há uma vasta literatura disponível sobre a delimitação de bacias usando SIG e MDE's, como verificado nos trabalhos de Jenson (1991), Leão et al. (2004) e Pereira e Ficher (2015). Ainda assim, em geral, as metodologias são aplicadas para delimitar bacias com grandes áreas, como nos trabalhos de Sobrinho et al. (2010) e Zanfir e Simulescu (2011), os quais delimitaram bacias com 365 e 2485 km², respectivamente, enquanto que o presente trabalho foca na delimitação de microbacias de aproximadamente $1 \mathrm{~km}^{2}$.

Além disso, os métodos de delimitação de bacias em SIG, usualmente, não utilizam parâmetros, como o ponto de exutório da bacia ou a ordem da bacia, para definir a abrangência da delimitação. Sem parâmetros, os programas demarcam bacias hidrográficas com proporções diversas, e dificilmente microbacias, em especial as que possuem rios de pequena ordem e extensão.

Diante do exposto, o objetivo deste trabalho é aplicar um método prático de delimitação de microbacias hidrográficas de pequena ordem a partir de um ponto de exutório específico (pour point), em SIG, utilizando dados de MDE da SRTM com pixel de $30 \mathrm{~m}$.

\section{Metodologia}

Trabalhou-se em doze áreas distribuídas em cinco estados brasileiros: Paraná, São Paulo, Rio Grande do Sul, Goiás e Mato Grosso do Sul. Os locais de estudo encontram-se em fazendas agrícolas, em terrenos de baixa declividade. Em cada área foi instalada uma estação hidrossedimentológica em uma porção retilínea de um córrego de pequena ordem. A posição dessa estação, em cada área de estudo, define o exutório da microbacia que se deseja delimitar, de modo a definir a área de contribuição da microbacia.

A metodologia de delimitação de bacias hidrográficas a partir de um ponto de exutório, descrita por Amanajás e Funi (2015) e fundamentada em Mark (1984) e Jenson e Dominique (1988), foi aplicada no programa ArcGIS versão 10.2 (ESRI, Redlands, EUA), usando MDE's de $30 \mathrm{~m}$ da SRTM das doze áreas de estudo. Empregaram-se as extensões Spatial Analyst, Conversion e Cartography, conforme detalhado abaixo. Os MDE's da SRTM de $30 \mathrm{~m}$ foram baixados gratuitamente do sítio EarthExplorer do United States Geological Survey (https://earthexplorer.usgs.gov). 
No MDE de cada área de estudo usou-se o comando Fill para detectar e preencher as depressões espúrias do modelo. Então, calculou-se a direção de fluxo da água (Flow Direction) e, em seguida, o fluxo acumulado de água em cada pixel (Flow Accumulation), atribuindo-lhe formato do tipo inteiro (Integer).

Feito isto, utilizou-se a função Conditional na ferramenta Raster Calculator com a finalidade de visualizar a rede de drenagem, mostrando somente os pixels com acúmulo de água maior do que 10 (Flow Accumulation > 10), com a seguinte expressão: Con(Flow Accumulation > 10, 1). Ressalta-se que o valor de acúmulo de água de 10 foi escolhido por tentativa e erro, buscando-se a melhor visualização da rede de drenagem, de acordo com a escala e objetivos propostos, sendo que, quanto menor o valor, maior o detalhamento da rede. Essa etapa de visualização da rede de drenagem é importante para conferir o posicionamento do ponto de exutório e corrigi-lo, se for o caso. Assim, quando o ponto de exutório encontrou-se fora da rede de drenagem, ele foi reposicionado manualmente para o pixel mais próximo localizado sobre a rede de drenagem.

Com o ponto de exutório verificado ou corrigido, o próximo passo foi executar a ferramenta Watershed para delimitar a área da bacia hidrográfica fornecendo-lhe o ponto específico de exutório (pour point). Finalmente, o arquivo raster gerado pela função Watershed foi convertido para shapefile pela ferramenta Raster to Polygon com a opção Simplify Polygons ativada, e o novo arquivo foi suavizado pela ferramenta Smooth Polygon usando o Bezier Interpolation como algoritmo de suavização.

Para conferência dos produtos gerados, as doze microbacias delineadas foram contrastadas com MDE's e imagens multiespectrais do sensor orbital Pléiades (Airbus Defence and Space, Toulouse, França) ou do sensor aerotransportado Ultracam D (Vexcel Corp., Boulder, EUA), ambos reamostrados para pixel de 1 m. Os MDE's foram obtidos após o processamento de pares estéreos do satélite Plêiades ou de imagens de aerolevantamento, cujas foram ortorretificadas na escala 1:10.000. Ademais, foram geradas curvas de nível com equidistância de $5 \mathrm{~m}$ a partir destes MDE's. Buscou-se verificar a adequação do delineamento das microbacias, tanto em relação à altimetria de alta resolução espacial e posicionamento das curvas de nível, como em relação à cobertura da terra, já que muitas vezes a cobertura está ligada aos padrões de relevo.

\section{Resultados e Discussão}

As microbacias delimitadas tiveram áreas de contribuição variando de 0,14 a 2,92 km², com média de 0,99 $\mathrm{km}^{2}$, e perímetros entre 1,5 e 8,63 km, com média de 4,2 km. Poucos estudos de delimitação obtiveram resultados com essa pequena dimensão, como, por exemplo, Leão et al. (2004), que demarcaram uma bacia de 3,3 km². A maioria dos trabalhos são focados em bacias de maior extensão, como em Pereira e 
XVII Simpósio Brasileiro

de Geografia Fisica Aplicada

I Congresso Nacional

de Geografia Física
OS DESAFIOS DA GEOGRAFIA FÍSICA NA FRONTEIRA DO CONHECIMENTO

Instituto de Geociências - Unicamp

Campinas - SP

28 de Junho à 02 de Julho de 2017

Ficher (2015) e Zanfir e Simulescu (2011), que delimitaram bacias hidrográficas com 683 e 2485 km², respectivamente. As delimitações obtidas foram consideradas satisfatórias, mesmo que em poucos casos tenham sido encontradas pequenas discrepâncias entre as delimitações e os dados de alta resolução espacial. Como exemplo, os resultados da delimitação de 3 microbacias são mostrados na Figura 1, sendo uma em Toledo (PR), com 1,11 km² (Figura 1B), e duas em Itaí (SP), uma com 0,50 (Figura 1C) e outra com $0,43 \mathrm{~km}^{2}$ (Figura 1D).

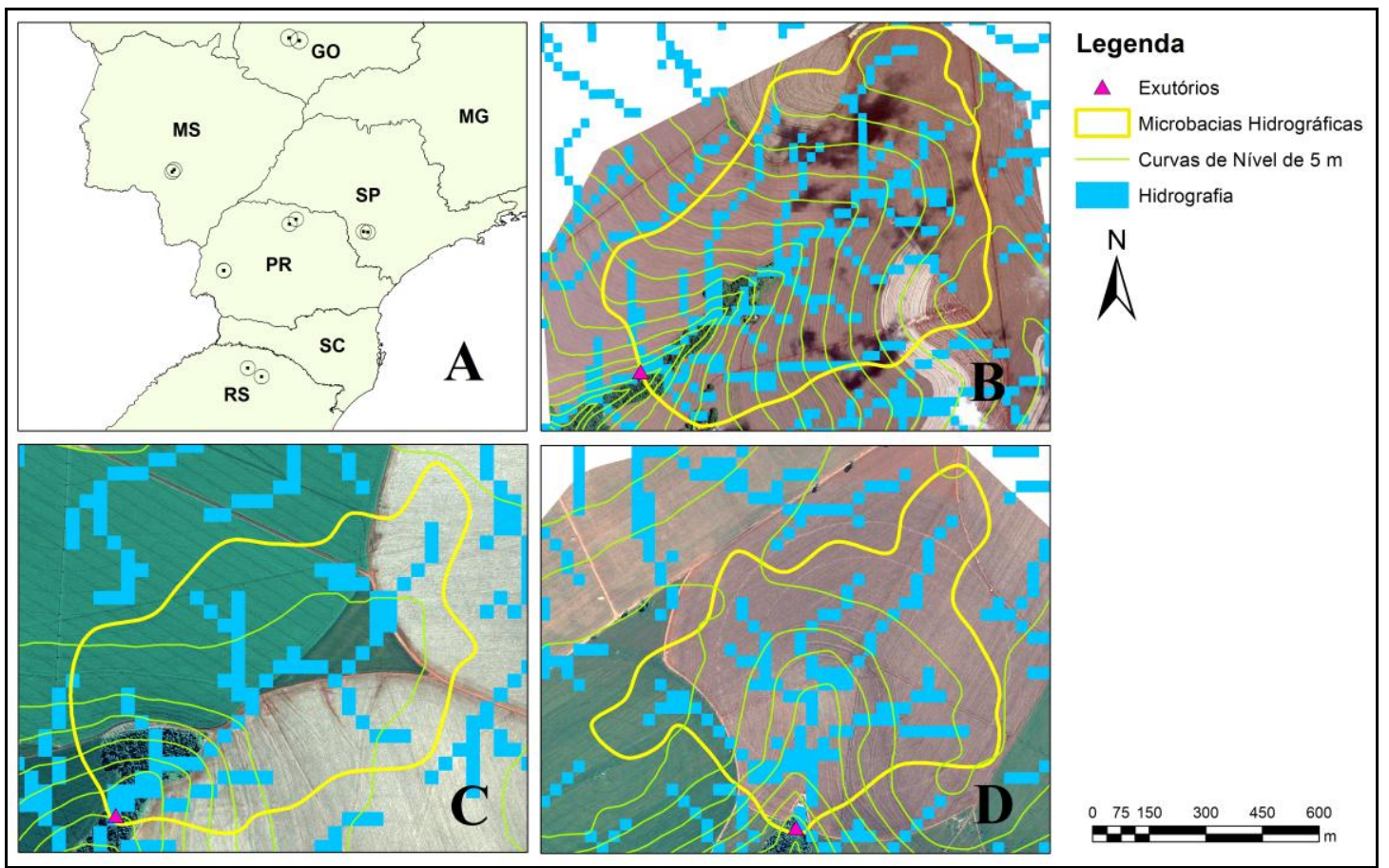

Figura 1 - Localização das doze microbacias hidrográficas em cinco estados (A) e resultados da delimitação de três microbacias hidrográficas, localizadas em Toledo (PR) (B) e Itaí (SP) (C e D), respectivamente.

Cherem et al. (2009) fazem objeção à extração de redes de drenagem a partir de MDE da SRTM em escala de estudo maior do que 1:100.000. Todavia, no presente trabalho, os resultados adquiridos a partir do MDE SRTM de $30 \mathrm{~m}$ foram, em geral, compatíveis com bases cartográficas na escala 1:10.000. Foi possível extrair a rede de drenagem das bacias com grande riqueza de detalhes mesmo para os rios de menor ordem e comprimento, que eram os mais presentes nas áreas estudadas.

Em alguns casos, foi necessário reposicionar o ponto do exutório, quando o mesmo se encontrava fora da rede de drenagem, utilizando-se como base o recurso visual gerado pela função Conditional. Caso esse reposicionamento não fosse feito, a ferramenta Watershed produziria uma delimitação de bacia inconsistente, às vezes limitada a somente um pixel. Essa limitação do método, apesar de não ter causado problemas sérios, deve ser levada em conta, sendo recomendada a aquisição mais precisa possível das coordenadas dos pontos de exutório no campo. 


\section{Conclusões}

A metodologia empregada permitiu delimitar pequenas microbacias hidrográficas utilizando pontos de exutório pré-determinados, possibilitando o maior controle da ordem e do tamanho da bacia hidrográfica pelo analista. Ela se mostrou adequada para delimitar bacias hidrográficas de pequena ordem e pequena extensão, ainda que a resolução espacial do MDE de entrada tenha sido de $30 \mathrm{~m}$.

A comparação dos resultados obtidos com bases cartográficas de alta resolução espacial $(1 \mathrm{~m})$ permitiu verificar a qualidade dos mesmos. Ainda assim, cabe o emprego de outras fontes de dados para assegurar ainda mais a precisão da delimitação, como cartas topográficas e pontos cotados. Ademais, se recomenda o uso desta metodologia para o estudo inicial de bacias hidrográficas que possuam poucos dados e/ou registros cartográficos, à vista de sua praticidade, baixo custo e produção de resultados padronizados.

\section{Agradecimentos}

Ao Núcleo de Geomática (NGeo) da Embrapa Solos, pelo apoio, e à Embrapa e à Itaipu Binacional, pelo suporte financeiro via projeto “Aprimoramento de Processos para a Qualificação do Manejo de Terras no Centro-Sul do Brasil” (No. 02.12.12.004.00.01).

\section{Referências}

AMANAJÁS, V.; FUNI, C. Mini curso de delimitação de Bacia Hidrográfica. 2015. Disponível em: <http://www.academia.edu/12889400/Delimitação_de_bacia_hidrográfica>. Acesso em: 10 set 2016.

CHEREM, L. F. S.; MAGALHÃES JUNIOR, A. P.; FARIA, S. D. Análise morfológica de rede de drenagem extraída de MDE-SRTM. In: SIMPÓSIO BRASILEIRO DE SENSORIAMENTO REMOTO, 14., 2009, Natal. Anais... São José dos Campos: INPE, 2009. p. 7251-7258.

JENSON, S. K. Applications of hydrologic information automatically extracted from digital elevation models. Hydrological Processes, v. 5, p. 31-44, 1991.

JENSON, S. K.; DOMINGUE, J. O. Extracting topographic structure from digital elevation data for geographic information system analysis. Photogrammetric Engineering and Remote Sensing, v. 54, p. 1593-1.600, 1988.

LEÃO, R. A. O.; TEIXEIRA, A. S.; ANDRADE, E. M.; OLIVEIRA, F. Delimitação e caracterização automática de uma micro-bacia hidrográfica da Fazenda Experimental Vale Curu, Pentecoste - CE. Revista Ciência Agronômica, v. 35, p. 26-35, 2004.

MARK, D. M. Automatic detection of drainage networks from digital elevation models. Cartographica, v. 21, p. 168-178, 1984. 
PEREIRA, D. R.; FICHER, K. N. Delimitação de bacia hidrográfica a partir de diferentes modelos digitais de elevação. In: CONGRESSO NACIONAL DE IRRIGAÇÃO E DRENAGEM, 25., 2015, Sergipe. Anais... 2015. p. 1289-1294.

SOBRINHO, T. A.; OLIVEIRA, P. T. S.; RODRIGUES, D. B. B.; AYRES, F. M. Delimitação automática de Bacias Hidrográficas utilizando dados SRTM. Engenharia Agrícola, v. 30, p. 46-57, 2010.

ZANFIR, A.; SIMULESCU, D. Automatic delineation of a watershed using a DEM. Case study: the Oltet watershed. Georeview, v. 20, p. 83-92, 2011. 